\title{
Evaluation of the Effect of Education Provided by Pharmacists on Hyperlipidemic Patient's Adherence to Medications and Blood Level of Lipids
}

\author{
Maryam Mehrpooya', Amir Larki-Harchegani², Davoud Ahmadimoghaddam², Mitra Kalvandi', Younes Mohammadi ${ }^{3}$, \\ Masoumeh Taravati Javad", Sara Ataei' \\ 'Department of Clinical Pharmacy, School of Pharmacy, Hamadan University of Medical Sciences, Hamadan, Iran. \\ 'Department of Pharmacology and Toxicology, School of Pharmacy, Hamadan University of Medical Science, Hamadan, Iran. \\ ${ }^{3}$ Modeling of Noncommunicable Diseases Research Center, School of Public Health, Hamadan University of Medical Sciences, Hamadan, Iran. \\ ${ }^{4}$ MSc. of Midwifery Consulting, Department of Midwifery, Hamadan University of Medical Sciences, Hamadan, Iran.
}

\section{ARTICLE INFO \\ Article history: \\ Received on: 17/09/2017 \\ Accepted on: 14/11/2017 \\ Available online: 28/01/2018}

\section{Key words:}

High blood cholesterol levels, Medication Adherence, Lipids.

\begin{tabular}{l}
\hline ABSTRACT \\
Background: Hyperlipidemia is one of the most common chronic diseases. Studies show that many patients have sub- \\
optimal adherence to statin medication which leads to serious negative health consequences. The aim of this study was \\
the evaluation of the effect of education by pharmacists for hyperlipidemic patients treated with statins on patient's \\
adherence to medication and their level of blood lipids. \\
Material \& Methods: This clinical trial included 50 patients with heart disease treated with statins who referred to \\
the Hamadan Farshchian Hospital from January to June 2016 . The study's data collection tools included a demograph- \\
ic and Morisky questionnaire and their lipid profile before and 6 month after intervention. Data were analyzed by \\
SPSS/16 using T-test, Mann-Withney and X2 tests. \\
Results: Data analysis reflects the homogeneity of medication adherence and the levels of lipid profile in both groups \\
before the intervention but after intervention the medication adherence increased in the intervention group (p $<0.001$ ) \\
and level of LDL significantly decreased (p $=0.02$ ), however, after the intervention there were no statistical difference \\
in the level of HDL, triglyceride and total cholesterol in both groups. \\
Conclusion: Findings of the study suggest that educational counseling by pharmacists could have a positive role in \\
patient's adherence to drugs and blood level of LDL.
\end{tabular}

\section{INTRODUCTION}

Lipids play a major role in many critical functions of body but their increase above normal level can elevate the risk of cardiovascular diseases. Studies in Iran have shown that approximately $23.9 \%$ of men and 12.4 percent of women in the general population suffer from hypercholesterolemia. According to a study, blood lipid abnormalities have been reported in about 54 percent of Tehran residents (Majdi et al., 2012).

${ }^{*}$ Corresponding Author

Masoumeh Taravati Javad, MSc. of Midwifery Consulting, Department of Midwifery, Hamadan University of Medical Sciences, Hamadan, Iran. E-mail:Taravati.masoome@gmail.com
Furthermore, elevated blood cholesterol is one of the main predisposing factor for heart disease which is controllable. After therapeutic lifestyle modification, statin medication is considered as a primary treatment for elevated low-density lipoprotein cholesterol (LDL-C) and hypercholesterolemia. Statins also reduce the rate of cardiovascular disease and decrease the rate of mortality in high-risk patients. It should be mentioned that statin medications can decreases major vascular problems such as atherosclerosis, non-fatal myocardial infarction (MI), coronary bypass, or stroke. only $40 \%-60 \%$ of patients who use statin treatment, adhere to it properly only to benefit from the advantages of the medication (Molfenter et al., 2012; Wei et al., 2013).

The ATP-III (Adult Treatment Panel third report) guidelines has identified patients with established cardiovascular dis- 
ease or diabetes and low-density lipoprotein (LDL) Cholesterol levels of $100 \mathrm{mg}$ per deciliter or higher are considered as candidates for statin therapy (Pencina et al., 2014).

In the United States it is estimated that about 125,000 deaths per year are due to non-adherence to medication and between $33 \%$ and $69 \%$ of hospitalizations were due to low adherence (Dias et al., 2014). Individuals with high long-term adherence have demonstrated greater cardiovascular disease risk reduction as compared with individuals with poor adherence (Wei et al., 2013). Adherence encompasses many health-related behaviors that extend beyond taking the prescribed pharmaceuticals (Sabaté, 2003). In other words, the adherence results from a balance between the perception of the need to take medication and concerns about their adverse effects (Dias et al., 2014). According to WHO report in developed countries, long-term medications adherence in the general population is about $50 \%$ and is much lower in developing countries (Sabaté, 2003). In most observational studies and clinical trials, rate of long-term adherence with statins are suboptimal, with approximately $50 \%$ adherence at 6 months and $25 \%$ adherence at 1 year (Wei et al., 2013). Medication adherence usually refers to whether patients take their medications as prescribed, as well as whether they continue to take a prescribed medication (Ho et al., 2009). The cost-benefit analysis of adherence to medication in patients suffering from hyperlipidemia show that for every additional dollar spent on adherence the costs would reduce by 5.10 dollars (Dias et al., 2014). Also ineffective prescription of physicians and Non-adherent patients lead to suboptimal lipid control (Aspry et al., 2013). Health care providers have an important impact on patient adherence to medication (Wei et al., 2013). Therefore, pharmacists are in contact with patients and get involved in counseling with them. In this pursuit, the pharmacist's activities include in enhancing the patient's knowledge and supporting the patients' medication management. These activities do not always lead to fully satisfactory results, especially with regard to medication side effects (Blom and Krass, 2011). Several studies demonstrate that patient counseling with regard to statin benefits, side effects, and the importance of adherence by community pharmacists or physicians can improve adherence and help patients to overcome barriers on the way of adherence (Taitel et al., 2012; Wei et al., 2013). Also involving the patient in the process of treatment and educating them are effective ways for improving drug adherence. The problem with non-adherence patient is not only the failure to achieve the goals of treatment, but it is also associated with the increased risk of hospitalization, mortality and medical costs (Amal et al., 2015). Pharmacists are equipped to educate and counsel patients on the importance of medication adherence and drugs adverse effects. Moreover, patients who receive counseling on medication grow to be more knowledgeable, have more positive beliefs about medication, and are more likely to adhere to treatment (Van Geffen et al., 2011).

Studies show that many patients have suboptimal adherence to statin medication which leads to serious negative health consequences. On this ground, the aim of this study was the evaluation of the effect of education by pharmacists for hyperlipidemic patients treated with statins on patient's adherence to medication and their level of blood lipids including total cholesterol, LDL, HDL and triglyceride.

\section{MATERIALS AND METHOD}

\section{Study design and subjects}

This interventional clinical trial study was conducted according to the declaration of Helsinki principles. Therefore, the objectives of the study were explained to the patients, and the informed consent was obtained from all participants. Participants could leave the study at any time.

In this clinical study, the studied population include the patients with heart disease who are treated with statins while attending the Hamadan Farshchian Hospital, Iran, between January and June 2016. To this aim, sixty patients with heart disease treated with statins expressed interest in the study. Ten patient were excluded due to the failure to meet inclusion criteria or due to declining interest. Fifty patients were stratified randomly using blocked randomization method and divided into two twenty five member groups of intervention and control. Randomization assignments prepared by an investigator with no clinical involvement in the trial. Participants who had the eligibility criteria were randomized to either the intervention group $(\mathrm{n}=25)$ or the control group $(\mathrm{n}=25)$.

\section{Intervention}

In this study, the intervention group received counseling about heart disease, hyperlipidemia, lipid profile, benefits of therapeutic lifestyle modification and statin adherence for one hour by the pharmacist. Data collection was performed before educational session and after 6 months. Data collection was based on the following parameters: patient demographic characteristics such as age, gender, level of education; history of heart disease and statin therapy, type of the drug used, duration of therapy; Number of daily additional medications; self-reported adherence to statin using validated 4-item Morisky medication adherence scale that has been shown to be predictive of the patients' adherence to cardiovascular medications (Shalansky et al., 2004).

In this study, adequate adherence is defined as a response of "no" to all 4 questions and inadequate adherence as a "yes" response to any one of 4 questions. The advantages of using this scale over other methods of evaluating adherence are rapid administration and ease of its using in a busy clinic setting (Pencina et al., 2014). Lipids profile of serum including total cholesterol, LDL, HDL and triglyceride were measured before and after 6 months.

At the end, the results were obtained in these two steps that is before and after intervention and the collected data were analyzed accordingly.

For ethical considerations, the educational counseling for control group was provided by the end of the study.

\section{Ethical considerations}

The study was approved by the Ethical Committee of Hamadan University of Medical Sciences (approval number: IR.UMSHA.REC.1395.11). Also, the trial was registered with the Iranian registry of clinical trials (IRCT201604119014N95).

\section{Statistical analysis}

Data were analyzed in SPSS/16 using T-test, Mann-Withney and X2 tests and the p-value $<0.05$ was regarded as significant. 


\section{RESULTS AND DISCUSSIONS}

The main objective of this study was to determine the effectiveness of educational intervention by the pharmacists on statins-treated hyperlipidemic patient's adherence to statin medication and their level of blood lipids.

Table 1: The demographic features of patients.

\begin{tabular}{|c|c|c|c|c|c|c|}
\hline \multicolumn{2}{|c|}{ Descriptive features } & \multicolumn{2}{|c|}{$\begin{array}{c}\text { Intervention } \mathbf{G} \text {. } \\
\quad \mathbf{N}=\mathbf{2 5}\end{array}$} & \multicolumn{2}{|c|}{$\begin{array}{c}\text { Control G. } \\
\mathbf{N}=\mathbf{2 5}\end{array}$} & \multirow{2}{*}{$\begin{array}{c}P \\
\text { value }\end{array}$} \\
\hline & & $\mathbf{F}$ & $(\%)$ & $\mathbf{F}$ & $(\%)$ & \\
\hline \multirow{3}{*}{ Education } & Illiterate & 10 & 40 & 5 & 20 & \multirow{3}{*}{0.27} \\
\hline & $\begin{array}{c}\text { Below High } \\
\text { school diploma }\end{array}$ & 8 & 32 & 9 & 36 & \\
\hline & $\begin{array}{l}\text { Higher educa- } \\
\text { tion }\end{array}$ & 7 & 28 & 11 & 44 & \\
\hline \multirow{2}{*}{ Gender } & Male & 10 & 40 & 6 & 24 & \multirow{2}{*}{0.22} \\
\hline & Female & 15 & 60 & 19 & 76 & \\
\hline
\end{tabular}

Regarding demographic information, there was no significant difference between the characteristics of the control and the intervention groups (Table 1). Average age of patients in the intervention group was $53.72 \pm 4.80$ years and average age of control group was $49.64 \pm 10.00$ years $(\mathrm{P}=0.07)$. Average duration of illness for control group's patients was $3.72 \pm 2.42$ years and for intervention group was $3.40 \pm 2.46$ years $(\mathrm{P}=0.31)$. There were no significant differences in the age and average duration of illness for both groups before the intervention.

Data analysis reflects the homogeneity of the adherence to statin therapy using Morisky Medication Adherence Scale in both groups before the intervention $(\mathrm{p}=0.49)$. The results showed that after intervention the adherence to the therapy in the intervention group significantly increased $(p<0.001)$ as compared to control group and the mean score of adherence for intervention group before and after intervention significantly increased $(p<$ 0.001 ) but it didn't changed significantly for the control group ( $\mathrm{p}$ $=0.35$ ) (Table 2).

The relationship between the mean adherence to medication and patient demographic characteristics like gender, age and education were evaluated at the beginning of the study and the results showed that there were no significant differences between this characteristics and adherence to medication in both groups (Table 3).

According to the results after the intervention, the blood level of LDL in patients in intervention group significantly decreased $(p=0.02)$, but after the intervention there were no statistical difference in the blood level of HDL, triglyceride and total cholesterol for both groups (Table 4).

The decrease in mean of total cholesterol and triglyceride and the increase in the HDL were observed in the intervention group, though they were not statistically significant.

The research results showed that after intervention (counseling provided by the pharmacist) the medication adherence increased in the intervention group and the level of LDL significantly decreased, yet after intervention there were no statistical difference in the level of HDL, triglyceride and total cholesterol in both groups. This confirms the point that the physicians and pharmacists have an important role in counseling to the patients about medication's benefits, risks and correct use (Blom and Krass, 2011).

Table 2: The mean score of medication adherence before and after intervention.

\begin{tabular}{lccc}
\hline Medication & $\begin{array}{c}\text { Intervention } \\
\text { Group } \\
\text { Adherence }\end{array}$ & $\begin{array}{c}\text { Control } \\
\text { Group }\end{array}$ & \multirow{2}{*}{ P value } \\
\cline { 2 - 3 } & Mean $\pm \mathbf{S D}$ & Mean $\pm \mathbf{S D}$ & \\
\hline Before & $7.92 \pm 3.86$ & $8.80 \pm 2.56$ & 0.49 \\
After & $11.32 \pm 1.90$ & $9.52 \pm 2.06$ & $\mathrm{p}<0.001$ \\
P value & $\mathrm{p}<0.001$ & 0.35 & \\
\hline
\end{tabular}

Table 3: The relationship between the mean adherence to medication and the demographic characteristics of both groups before intervention.

\begin{tabular}{|c|c|c|c|c|c|}
\hline \multirow{3}{*}{\multicolumn{2}{|c|}{$\begin{array}{l}\text { Demographic } \\
\text { characteristics }\end{array}$}} & \multicolumn{4}{|c|}{ Adherence to medication } \\
\hline & & \multicolumn{2}{|c|}{ Intervention Group } & \multicolumn{2}{|c|}{ Control Group } \\
\hline & & Mean \pm SD & $\begin{array}{c}\mathbf{P} \\
\text { value }\end{array}$ & Mean \pm SD & $\begin{array}{c}P \\
\text { value }\end{array}$ \\
\hline \multirow{2}{*}{ Gender } & Male & $8.33 \pm 4.03$ & \multirow{2}{*}{0.59} & $8.60 \pm 2.71$ & \multirow{2}{*}{0.72} \\
\hline & Female & $7.68 \pm 3.78$ & & $8.93 \pm 2.54$ & \\
\hline \multirow{3}{*}{ Age } & $<50$ years & $7.28 \pm 4.71$ & \multirow{2}{*}{0.76} & $9.06 \pm 2.43$ & \multirow{2}{*}{0.53} \\
\hline & $\geq 50$ years & $8.16 \pm 3.60$ & & $8.33 \pm 2.87$ & \\
\hline & Illiterate & $9.10 \pm 3.87$ & & $8.55 \pm 2.38$ & \multirow{3}{*}{0.69} \\
\hline \multirow[t]{2}{*}{ Education } & $\begin{array}{c}\text { Below High } \\
\text { school } \\
\text { diploma }\end{array}$ & $6.85 \pm 3.75$ & 0.27 & $9.23 \pm 2.55$ & \\
\hline & $\begin{array}{l}\text { Higher } \\
\text { education }\end{array}$ & 11 & & $8.25 \pm 2.86$ & \\
\hline
\end{tabular}

This study's finding with regard to the effectiveness of good pharmacist-patient relationship and counseling in increasing medication adherence is consistent with the result of a cross-sectional study conducted by Amal et al. In this study authors have pointed out that predictors of high adherence are good physician-patient relationship and counseling, a high level of health-related quality of life and perceived health, and predictors of low adherence included a reducing memory, anxiety/depression, low knowledge about drug, and delay in appointments with physician (Amal et al., 2015). Taitel et al. in a research came to this conclusion that patients who profited by consultation of pharmacist before they started to use the statins have significantly better adherence than the control group which is in line with the result of this study (Taitel et al., 2012). Cohen also in a survey suggests that further helpful conversation between health professional and patients may enhance the adherence to drug, especially when the client has concerns about adverse reactions to drug and the medication costs (Cohen et al., 2012).

Findings of other studies demonstrated similar results with regard to pharmacist interventions can improve adherence of patients to the medications (Clifford et al., 2006; Cutrona et al., 2010; Kripalani et al., 2007; Lee et al., 2006).

In a cross-sectional study conducted by Castellucci et al. using the Morisky scale predictors of adherence to the antico- 
agulation drugs were age, female gender, use of additional oral medications, and occupation status (Castellucci et al., 2015). Also other surveys have demonstrated that age and gender are significant factors contributing to better adherence of patients to medication (Davis et al., 2005; Gorst-Rasmussen et al., 2015). But, in this study, such factors as age, gender and education level had no effect on adherence to treatment that could be due to the small sample size of patients. This finding is consistent with the results of another study reported which concludes none of the socio-demographics variables significantly affected the drug adherence (Amal et al., 2015).

Table 4: Comparing lipid profiles in groups before and after intervention.

\begin{tabular}{lcccc}
\hline \multirow{2}{*}{ Lipid profile mg/dl } & $\begin{array}{c}\text { Intervention } \\
\text { group }\end{array}$ & Control group & $\begin{array}{c}\text { P } \\
\text { value }\end{array}$ \\
\cline { 3 - 4 } & Mean \pm SD & Mean \pm SD & \\
\hline Total & Before & $187.44 \pm 23.85$ & $196.56 \pm 36.95$ & 0.30 \\
cholesterol & After & $168.56 \pm 31.06$ & $180.16 \pm 36.95$ & 0.05 \\
LDL & Before & $104.34 \pm 38.24$ & $108.68 \pm 30.99$ & 0.57 \\
& After & $91.80 \pm 27.18$ & $102.04 \pm 30.99$ & 0.02 \\
HDL & Before & $43.48 \pm 8.51$ & $45.40 \pm 8.51$ & 0.90 \\
& After & $46.09 \pm 9.16$ & $45.40 \pm 8.51$ & 0.85 \\
\multirow{2}{*}{ Triglyceride } & Before & $199.88 \pm 138.27$ & $196.60 \pm 126.99$ & 0.86 \\
& After & $144.60 \pm 60.70$ & $186.56 \pm 126.99$ & 0.87 \\
\hline
\end{tabular}

Result of this research demonstrated that intervention can significantly decrease the level of LDL-C. Also changes were observed in mean of total cholesterol, HDL and Triglyceride in each group, though they were not statistically significant. In a cohort study, that evaluated clinical pharmacists' supporting effect on diabetic and/or hyperlipidemic patient's LDL-C, TGs, and BMI, the results revealed changes in mean of LDL-C, TGs, and BMI, however, this again was not statistically significant (Hetro et al., 2015). Pape et al. have conducted a research to evaluate the impact of remote physician-pharmacist team-based care on blood cholesterol levels in diabetic patients and they came to this finding that during the 24-month follow-up remotely located physician-pharmacist team-based care can significantly improve blood LDL-C level (Pape et al., 2011). In a survey, Bunting et al. concluded that pharmacist's consultation can improve the lipid levels of diabetic patients which is in line with result of present study (Bunting et al., 2008). Also, a project carried out by Bluml et al. showed that counseling by pharmacists can improve adherence and lipid levels in patients with imperfect control of lipids (Bluml et al., 2000).

The present study has some limitations. Limitations of this study include the small sample size of the patients of the study and short duration of the study. There may be other factors as well such as taking simultaneous medications and the presence of other diseases the patient might suffer from at the same time. Thus, more research is needed to be done with more samples within longer time period.

\section{CONCLUSION}

In conclusion, the findings of this study highlight the important role of counseling provided by the pharmacist which can have a significant impact on improving patients' adherence to statin therapy and the reducing the blood LDL level while having potential reductions in morbidity and mortality. Also, by enhancing communication between the pharmacist and the patient, we will reach to more opportunity for attaining the goal of medication treatment and at the same time improving the patient's adherence to the therapy.

Further studies are recommended to consider the effectiveness of these interventions and other effective interventions in improving the status of patients with other chronic diseases.

\section{ACKNOWLEDGEMENTS}

This paper is part of the thesis by Ms. Mitra Kalvandi for the degree of doctor of pharmacy. The authors sincerely acknowledge the Hamadan University of Medical Sciences in Iran for their valuable support and participation. Hereby, the authors would like to gratefully thank the patients for participating in the study.

\section{CONFLICT OF INTEREST}

The authors hereby declare that they have no conflict of interest.

\section{REFERENCES}

Amal A-H, Awada S, Rachidi S, Salam Z, Bawab W, Zeinab E-H, et al. Factors affecting medication adherence in Lebanese patients with chronic diseases. Pharm Pract (Granada), 2015; 13:1-9.

Aspry KE, Furman R, Karalis DG, Jacobson TA, Zhang AM, Liptak GS, et al. Effect of health information technology interventions on lipid management in clinical practice: a systematic review of randomized controlled trials. J Clin Lipidol, 2013; 7:546-560.

Blom L, Krass I. Introduction: The role of pharmacy in patient education and counseling. Patient Educ Couns, 2011; 83:285-287.

Bluml BM, McKenney JM, Cziraky MJ. Pharmaceutical care services and results in Project ImPACT: Hyperlipidemia. J Am Pharm Assoc (1996), 2000; 40:157-165.

Bunting BA, Smith BH, Sutherland SE. The Asheville Project: clinical and economic outcomes of a community-based long-term medication therapy management program for hypertension and dyslipidemia. J Am Pharm Assoc (2003), 2008; 48:23-31.

Castellucci LA, Shaw J, Van Der Salm K, Erkens P, Le Gal G, Petrcich W, et al. Self-reported adherence to anticoagulation and its determinants using the Morisky medication adherence scale. Thromb Res, 2015; $136: 727-731$

Clifford S, Barber N, Elliott R, Hartley E, Horne R. Patient-centred advice is effective in improving adherence to medicines. Pharm World Sci, 2006; 28:165-170.

Cohen JD, Brinton EA, Ito MK, Jacobson TA. Understanding Statin Use in America and Gaps in Patient Education (USAGE): an internet-based survey of 10,138 current and former statin users. J Clin Lipidol, 2012; 6:208-215

Cutrona SL, Choudhry NK, Fischer MA, Servi A, Liberman JN, Brennan T, et al. Modes of delivery for interventions to improve cardiovascular medication adherence: Review. Am J Manag Care, 2010; 16:929.

Davis NJ, Billett HH, Cohen HW, Arnsten JH. Impact of adherence, knowledge, and quality of life on anticoagulation control. Ann Pharmacother, 2005; 39:632-636.

Dias A, Pereira C, Monteiro MJ, Santos C. Patients' beliefs about medicines and adherence to medication in ischemic heart disease. Aten Primaria, 2014; 46:101-106.

Gorst-Rasmussen A, Skjøth F, Larsen TB, Rasmussen LH, Lip GY, Lane DA. Dabigatran adherence in atrial fibrillation patients during the first year after diagnosis: a nationwide cohort study. J Thromb Haemost, 2015; 13:495-504. 
Hetro A, Rossetto J, Bahlawan N, Ryan M. Clinical pharmacists supporting patients with diabetes and/or hyperlipidemia in a military medical home. J Am Pharm Assoc, 2015; 55:73-76.

Ho PM, Bryson CL, Rumsfeld JS. Medication adherence its importance in cardiovascular outcomes. Circulation, 2009; 119:3028-3035.

Kripalani S, Yao X, Haynes RB. Interventions to enhance medication adherence in chronic medical conditions: a systematic review. Arch Intern Med, 2007; 167:540-549.

Lee JK, Grace KA, Taylor AJ. Effect of a pharmacy care program on medication adherence and persistence, blood pressure, and low-density lipoprotein cholesterol: a randomized controlled trial. JAMA, 2006; 296:2563-2571.

Majdi M, Nikparast N, Bagherzadeh A, Puradine M, Saberi kM, Khani $\mathrm{H}$, et al. The prevalence of hyperlipidemia and some effective factors in teachers of north khorasan province. J North Khorasan University of Medical Sciences, 2012; 4:87.

Molfenter TD, Bhattacharya A, Gustafson DH. The roles of past behavior and health beliefs in predicting medication adherence to a statin regimen. Patient Prefer Adherence, 2012; 6:643-651.

Pape GA, Hunt JS, Butler KL, Siemienczuk J, LeBlanc BH, Gillanders $\mathrm{W}$, et al. Team-based care approach to cholesterol management in diabetes mellitus: two-year cluster randomized controlled trial. Arch Intern Med, 2011; 171:1480-6.

Pencina MJ, Navar-Boggan AM, D’Agostino Sr RB, Williams K, Neely B, Sniderman AD, et al. Application of new cholesterol guidelines to a population-based sample. New Engl J Med, 2014; 370:1422-1431.
Sabaté E, 2003. Adherence to long-term therapies: evidence for action. World Health Organization.

Shalansky SJ, Levy AR, Ignaszewski AP. Self-reported Morisky score for identifying nonadherence with cardiovascular medications. Ann Pharmacother, 2004; 38:1363-1368.

Taitel M, Jiang J, Rudkin K, Ewing S, Duncan I. The impact of pharmacist face-to-face counseling to improve medication adherence among patients initiating statin therapy. Patient Prefer Adherence, 2012; 6:e329.

van Geffen EC, Philbert D, van Boheemen C, van Dijk L, Bos MB, Bouvy ML. Patients' satisfaction with information and experiences with counseling on cardiovascular medication received at the pharmacy. $\mathrm{Pa}$ tient Educ Couns, 2011; 83:303-309.

Wei MY, Ito MK, Cohen JD, Brinton EA, Jacobson TA. Predictors of statin adherence, switching, and discontinuation in the USAGE survey: understanding the use of statins in America and gaps in patient education. J Clin Lipidol, 2013; 7:472-483.

\section{How to cite this article:}

Mehrpooya M, Larki-Harchegani A, Ahmadimoghaddam D, Kalvandi M, Mohammadi Y, Javad MT, Ataei S. Evaluation of the Effect of Education Provided by Pharmacists on Hyperlipidemic Patient's Adherence to Medications and Blood Level of Lipids. J App Pharm Sci, 2018; 8 (01): 029-033. 